\section{Non-Alcoholic Fatty Liver Disease in Patients with Diabetes Mellitus: A Clinician's Perspective}

\section{Abstract}

Nonalcoholic fatty liver disease with its phenotypes fatty liver and steatohepatitis, is the most common cause of chronic liver disease worldwide and linked to the epidemic of diabetes mellitus and obesity. It is characterized by a high cardiovascular and liver-related mortality and expected to soon become the leading cause for liver transplantation. This concise review summarizes recent progress in the clinical management of patients with diabetes mellitus and nonalcoholic fatty liver disease and evaluates strategies to manage diabetes mellitus in terms of their effectiveness towards this epidemic liver disease.

Keywords: NAFLD; NASH; Insulin resistance; Hepatocellular carcinoma; Cryptogenic cirrhosis; Physical activity; Life style; Diet; Metformin; Thiazolidinediones; Nuclear receptor agonists

Received: September 16, 2015, Accepted: November 12, 2015, Published: November 19, 2015

\section{Scope of the Problem}

More than 25 million Americans are afflicted with diabetes mellitus [1], a common public health challenge worldwide expected to affect by 2030 nearly 600 million or more than $9 \%$ of the adult population [2, 3]. Type 2 diabetes mellitus, characterized by insulin resistance, accounts for more than $90 \%$ of diabetes forms and is now considered to represent the seventh leading cause of death in the US. A population-based study of diabetic patients living in the Social Health Unity of Verona showed that patients with diabetes mellitus had a higher mortality when compared with the general non-diabetic population [4]. More detailed analysis revealed that approximately $4 \%$ of allcause mortality is liver-related [5]. It is now well established that nonalcoholic fatty liver disease (NAFLD) is key to the known link between diabetes mellitus and liver mortality. The pathophysiological link between NAFLD and diabetes mellitus is beyond the scope of this review and has been reviewed in detail elsewhere [6]. Of note, development of NAFLD with progression to nonalcoholic steatohepatitis (NASH) on one hand and diabetes mellitus on the other hand involves alterations of several shared metabolic pathways in addition to environmental factors, genetic predisposition and epigenetic factors.

NAFLD, the most common liver disease worldwide, occurs in two distinct phenotypes that can be distinguished only based on liver histology, simple steatosis and $\mathrm{NASH}$, respectively. Of

\section{Sarah Kashanian ${ }^{1}$ and Michael Fuchs ${ }^{1,2}$}

\author{
Division of Gastroenterology, Hepatology \\ and Nutrition, Virginia Commonwealth \\ University Medical Center, Richmond, \\ VA, USA \\ 2 Hunter Holmes McGuire Department \\ of Veterans Affairs Medical Center, \\ Gastrointestinal and Hepatology Service, \\ Richmond, VA, USA
}

\section{Corresponding author: Michael Fuchs}

\section{Michael.Fuchs2@va.gov}

Hunter Holmes McGuire Department of Veterans Affairs Medical Center, Gastrointestinal \& Hepatology Service (111-N) McGuire DVAMC, 1201 Broad Rock Boulevard, Richmond VA 23249, USA.

Tel: 804-675-5802

Fax: 804-675-5816 these two phenotypes, only patients with NASH have a higher mortality over a period of up to 20 years when compared with the general population $[7,8]$. In this regard it is of great importance to understand that histologic features of NASH appear to be most relevant to short-term disease progression whereas the presence of liver fibrosis indicates a higher likelihood of dying or developing liver-related complications within one or two decades [9]. Unfortunately many subjects with NAFLD remain undiagnosed as many primary care providers and hospital specialists underestimate the prevalence of NAFLD in their patient population [10-13]. Paradoxically this holds particularly true for cardiologists and endocrinologists albeit NAFLD is most prevalent in type 2 diabetes mellitus and coronary artery disease, respectively $[14,15]$. Contributing to this is the fact that patients with NASH can have entirely normal plasma aminotransferases $[16,17]$. This observation has recently been confirmed for patients with diabetes mellitus [18]. In addition, providers still have the misconception that improving diabetes control alone will be sufficient to improve the natural history of NAFLD and therefore make NASH targeted treatment unnecessary. Interestingly, there is a low awareness of NAFLD in the general population as well as among patients with metabolic risk factors $[19,20]$. Implementing early prevention strategies and optimizing care is desired but will fail without systematic screening in asymptomatic high risk subjects and advanced liver disease will not be diagnosed. 
The purpose of this review is to increase the awareness of NAFLD in patients with diabetes mellitus, to explore the impact of diabetes therapy on NAFLD and to highlight new treatment avenues that benefit patients with both, NAFLD and diabetes mellitus, respectively.

\section{Diabetes Mellitus, NASH, Liver Cirrhosis and Hepatocellular Carcinoma}

The prevalence of NAFLD in the general US population is estimated to be $34 \%$ [21], 34-74\% in patients with diabetes mellitus [22] and $100 \%$ in obese patients with diabetes mellitus [23]. Diabetes mellitus is an independent risk factor for NAFLD and the risk appears to increase by $10-20 \%$ per rising $\mathrm{mmol} / \mathrm{l}$ fasting glucose levels $[24,25]$. In patients with diabetes mellitus, the diagnosis of NAFLD is usually made within 6 years after diagnosing diabetes [26]. Although the natural history of NAFLD is incompletely understood, it was thought that approximately $20 \%$ of patients with diabetes mellitus will develop NASH [27]. This is being challenged by the recent observation that $56 \%$ of diabetics with normal aminotransferases had biopsy-proven NASH [18]. The interactions between diabetes and NAFLD are complex and it has been shown that NAFLD is associated with an 3-5 fold increased risk to develop diabetes $[28,29]$. On a time scale diabetes may be diagnosed up to 4 years after diagnosis of NAFLD [26]. Of note, improvement of NAFLD has the potential to reduce the incidence of diabetes as has been shown in a recent retrospective 10 year follow-up study [30].

For reasons that are incompletely understood, only a portion of patients with NASH progress to liver cirrhosis. At the stage of cirrhosis, steatosis often disappeared supporting the notion that nearly $40 \%$ of previously diagnosed cryptogenic cirrhosis is recognized as NAFLD or burned-out NASH [31]. A large number of patients with cryptogenic cirrhosis have diabetes mellitus [32], again consistent with NASH leading to liver cirrhosis. Insulin resistance is present in up to $80 \%$ of patients with liver cirrhosis, irrespective of the etiology of cirrhosis [33]. Whereas insulin resistance and diabetes mellitus can develop as the liver function deteriorates [34, 35], it is believed to play a central role in the development of NAFLD.

For the past almost two decades it has been known that there is a three-fold risk of hepatocellular carcinoma (HCC) in patients with diabetes mellitus that do not have liver cirrhosis or other concomitant diseases that predispose to liver cancer [36]. The increased prevalence of hepatocellular carcinoma in patients with diabetes mellitus as well as the increased prevalence of diabetes mellitus in patients with liver cancer also suggests that NASH can lead to liver cancer in the diabetic population [37, 38]. Although the majority of HCC's appear to arise in cirrhotic livers with an estimated incidence of 2-3\% per year, a substantial proportion of cancers may occur in the absence of advanced fibrosis [39, 40]. A detailed characterization of these HCC's and patients is of critical importance to allow a better targeted HCC surveillance in NAFLD.

Examining the cause-specific mortality in patients with diabetes revealed that liver cirrhosis was a leading cause of death accounting for $4 \%$ of deaths. Compared with the general population the risk of dying due to cirrhosis was doubled [5]. In another European cohort of diabetics, liver cirrhosis accounted for $12.5 \%$ of deaths [41], confirming a link the between diabetes mellitus and liver cirrhosis described by Creutzfeldt more than forty years ago [42]. Although less common, type 1 diabetes mellitus also appears to be linked to a nearly 2-fold increase in liver cirrhosis when compared with the general population [43]. Notably, liver-related outcomes among patients with type 1 and type 2 diabetes mellitus were similar in this study.

\section{NAFLD, Diabetes Mellitus and Cardiovascular Disease}

Current evidence supports that NAFLD, irrespective of the methodology used to diagnose NAFLD, is associated with an increased risk of cardiovascular events in both non-diabetic and type 2 diabetic individuals. At first, this link will be attributed to the fact that NAFLD often presents with features of the metabolic syndrome that represent established risk factors for cardiovascular disease [44]. However, a growing body of evidence suggests that NAFLD and in particular its necroinflammatory state, NASH, is independent of classic risk factors associated not only with markers of subclinical atherosclerosis but also incident cardiovascular disease [45-48]. These observations are in support of cardiovascular events being the leading cause of death in NAFLD $[7,8,49,50]$. The biologic mechanisms involved in the increased cardiovascular risk are yet to be worked out. It is however likely that multiple players contribute to the increased cardiovascular risk, including pro-inflammatory markers and a pro-thrombotic state.

Due to the high risk for future cardiovascular events, patients with NAFLD should deserve special attention for cardiovascular screening and surveillance strategies. Although this strategy may lead to early intervention with improvement of prognosis, longterm studies to validate the value if ameliorating NASH will result in prevention of cardiovascular events are needed.

\section{Genetic Basis of Diabetes Mellitus and NAFLD}

Genome wide association studies that evaluate the genotypicphenotypic association in population-based cohorts have been performed in NAFLD [51]. Numerous genetic variants of cytokines and adipocytokines as well as genes influencing lipid metabolism, insulin signaling, oxidative stress, fibrogenesis and inflammation may account for the variability in susceptibility to NAFLD [52]. Only a small number of single nucleotide polymorphisms are linked to diabetes mellitus and NAFLD. TCF7L2 and GCKR appear to reflect an increased risk for diabetes mellitus and NAFLD [5355]. Among genes involved in lipid metabolism, APOB, APOC3 and MTTP [51] have been associated with diabetes mellitus and NAFLD whereas a sterol regulatory element-binding factor 2 polymorphism could predispose lean and non-diabetic subjects to develop not only NAFLD but also diabetes mellitus [56].

However, most of these genetic variants have not been validated by replication cohorts and, when compared with epigenetic modifiers [57], may affect only a small proportion of NAFLD phenotypes. It appears logic to assume that several genes are involved and interlinked in the pathogenesis of diabetes mellitus and NAFLD with a specific phenotype regulated by genes involved in diverse metabolic pathways. Novel information may be obtained by exploring the association of variation within multiple genes 
involved in a defined biologic pathway with a given phenotype [58]. Furthermore, information may be gained to determine to what degree constitutional genome variability within biologic processes promotes disease progression or response to treatment. Clearly, large collaborative studies including ethnically and geographic diverse populations are needed.

\section{Diagnosis of Non-alcoholic Fatty Liver Disease}

Diagnosis of non-alcoholic fatty liver disease requires demonstration of fatty liver in the absence of significant alcohol use ( $<30 \mathrm{~g}$ per day for men; $<20 \mathrm{~g}$ per day for women) and other coexisting liver diseases or other causes inducing fatty liver [59]. Therefore NAFLD clearly is a diagnosis of exclusion by employing clinical, laboratory and imaging studies. The image modality of choice to document the presence of fatty liver is abdominal ultrasound. It is widely available, portable, not associated with radiation exposure, non-invasive and not costly. It is ideally suited to examine large numbers of patients. The only caveat is the lack of sensitivity for less than $20-30 \%$ of fat and the low precision in grading NAFLD $[60,61]$. More accurate quantification of intrahepatic fat to detect even mild degrees of steatosis can be achieved with other imaging modalities such as computed tomography and magnetic resonance [62] but those modalities are expensive and not practical for routine use and screening of a larger number of subjects. Until today, no imaging techniques can reliably distinguish between steatosis and steatohepatitis.

\section{Assessment of Disease Severity}

Assessing disease severity becomes of particular importance as identifying patients with advanced fibrosis and cirrhosis allows screening for liver-related complications such as liver cancer. Current diagnostic standard is to perform a liver biopsy as it is the only reliable test to distinguish between simple steatosis and NASH while at the same time providing information regarding the extent of fibrosis. Liver biopsy, however, has clear limitations which include the invasive nature of the procedure with potential associated complications [63], sampling error particularly for small biopsy samples with underestimating disease severity [64], variability in pathologist interpretation, cost and inability to be performed in the clinic.

Research over the last years has attempted to substitute liver biopsy with a noninvasive test that would allow accurate diagnosis, grade and stage of nonalcoholic fatty liver disease. It is well established that advanced fibrosis can be present in patient with NAFLD that display mildly elevated or even normal liver enzymes $[17,65,66]$. Therefore liver enzymes such as ALT are not a good marker for disease stage. Serum IgA levels are lower in simple steatosis compared with $\mathrm{NASH}$, particularly in patients with diabetes mellitus. In addition, serum IgA levels are an independent predictor of advanced fibrosis [67], yet there is no clear cut threshold to allow distinguishing between steatosis and NASH. Several scoring systems based on laboratory tests or clinical findings have been evaluated and compared with liver biopsy $[66,68]$. None of the scoring systems is helpful to differentiate between simple steatosis and NASH, but each of them is able to reliably exclude advanced fibrosis in NAFLD and help avoid a significant number of unnecessary liver biopsies.
Unfortunately, these scoring systems did not perform well in the Edinburgh type 2 diabetes study [69]. This is surprising but may reflect aggressive treatment of diabetes [70] or a low prevalence of advanced fibrosis. Perhaps each scoring system requires its own range reflecting a specific population. On the other hand, routinely available clinical and biochemical factors obtained in patients with diabetes can help accurately classify $67 \%$ and $77 \%$ of diabetic patients with NASH and advanced liver fibrosis, respectively [71].

Elastography or liver stiffness measurements for assessment of disease activity (inflammation) and severity (fibrosis) have been explored in NAFLD employing ultrasound based transient elastography, acoustic radiation force impulse imaging and magnetic resonance elastography [72]. It is anticipated that particularly the new ultrasound based imaging modalities will be adopted in clinical practice rapidly clearly helping to avoid unnecessary liver biopsies. However, as the relative contributions of inflammation and fibrosis to liver stiffness measurements remain unknown, these tests unlikely can be used to monitor treatment response. Liver stiffness measurements with concomitant assessment of liver fat by assessing the controlled attenuation parameter is currently the most advanced noninvasive testing that could be used for screening diabetic and other high risk patients [73].

Employing high-throughput analysis based on genomics, lipidomics, proteomics and metabolomics in the post genomic era, will yield a wealth of information and provide a unique perspective of disease processes. It is hoped that these approaches will help identify biomarkers to not only accurately diagnose the various stages of NAFLD, but also to predict outcomes and responses to effective treatment once available [74].

\section{Clinical Management}

Although risk factors for NAFLD are well stablished, exact mechanisms that determine progression from pure steatosis to steatohepatitis and ultimately cirrhosis remain incompletely understood. Despite emerging novel therapeutic targets for NAFLD therapy [75], life style modification including diet and physical activity accompanied by drug therapy of diabetes mellitus remains the foundation how diabetic patients with NAFLD are currently managed.

\section{Life style modification}

Patients with diabetes mellitus and NAFLD are often overweight and therefore lifestyle interventions to achieve weight loss should play an important role in disease management. Of note, weight loss should be controlled and not too fast to avoid worsening of liver injury [76]. Reducing energy intake while maintaining a healthy diet will facilitate weight loss, particularly when combined with physical activity. Physical activity is an important part of the diabetes management plan [77]. Of note, a reduction in visceral fat and improvement of insulin sensitivity can already be achieved with minimal weight loss [78-81]. It is now recommended to perform a moderate-intensity physical activity (50-70\% of maximum heart rate) at least three times per week for a total of at least $2.5 \mathrm{hrs}$ [82-84]. However, patients with NAFLD have a low compliance with physical activity often due to fatigue [85]. 
The Western-style diet of patients with NAFLD is characterized by a high content of fructose corn syrup and saturated fatty acids whereas mono- and polyunsaturated fatty acids, fiber and antioxidants are less present [86-88]. Unlike glucose, fructose does not stimulate insulin or leptin secretion, effectively bypassing normal satiety signals and contributing to the observed increased caloric intake in patients with NAFLD [89]. In contrast, a Mediterranean diet rich in mono- and polyunsaturated and fatty acids may reduce liver fat and improve insulin resistance even without weight loss [90]. No specific dietary guidelines exist for NAFLD, but it is plausible that dietary recommendations for diabetes mellitus apply for NAFLD although their utility for treating NAFLD remains largely unknown [91]. In agreement with recommendations of the American Diabetes Association [77], patients with NAFLD should minimize or even avoid the consumption of high fructose corn syrup whereas the amount of consumed complex carbohydrates found in whole grains, legumes and vegetables should be increased. Limiting the dietary content of saturated fat ( $<7 \%$ of total calories) by increasing the amount of mono- and polyunsaturated fatty acids may be beneficial for NAFLD patients by promoting a favorable lipid profile, improving glucose levels and reducing liver inflammation and steatosis, respectively [92-94]. Until studies in the diabetic population with NAFLD as outcome are available to establish evidence-based guidelines, one can propose a dietary framework for patients with NAFLD that extrapolates from dietary guidelines aiming to improve insulin resistance [95].

Although an optimal strategy has not yet been worked out, sustainability of these modifications is paramount to their success but often difficult to accomplish and may require concomitant cognitive-behavioral approaches [96, 97]. It is also important to realize that many patients face barriers to success such as immobility, work schedules, limited access to quality food and an unsupportive environment, respectively. To promote long-term lifestyle modifications it appears equally important that patients will not only undergo an initial comprehensive counseling but also monitoring and ongoing evaluations with modifications of interventions as needed. Carefully designed and executed intervention trials in diabetic patients with NAFLD should provide the basis for future evidence-based lifestyle interventions.

\section{Insulin sensitizing agents}

Insulin resistance is a key pathophysiological factor in the development of NASH. Efforts to improve insulin sensitivity as therapeutic intervention is therefore not surprising and should be a primary goal, irrespective of the presence or absence of NAFLD as effective glucose control reduced complications in diabetes mellitus. Current standards of medical care in type 2 diabetes mellitus recommend the biguanide metformin as preferred initial pharmacological agent. The glucose-lowering effects of metformin are due to lowered gluconeogenesis, increased glucose uptake into muscle and increased fatty acid oxidation in adipose tissue, all considered due to activation of adenosine monophosphate-activated protein kinase [98]. Several small clinical trials using metformin are supporting a beneficial role in NAFLD [99]. These studies however were small in number, using different drug doses, employing diabetic and non-diabetic patients at various disease stages with limited available data to demonstrate histological improvement. Therefore larger randomized controlled trials of sufficient duration using clearly defined histological endpoints are needed to fully assess potential drug efficacy in modifying the natural history of NAFLD [59]. These studies may also be able to demonstrate presence or absence of protective effects towards liver cancer [100]. For daily clinical management of patients with diabetes mellitus and liver disease it is of particular importance to appreciate that metformin does not exacerbate nor cause liver injury and therefore no dose adjustments are needed in the presence of hepatic impairment $[101,102]$. However, development of lactic acidosis can occur when using metformin in patients with advanced liver cirrhosis in whom renal impairment is not uncommon [103].

Thiazolidinediones (TZDs) is another class of oral hypoglycemic agents that serve as insulin sensitizers. As selective agonists for peroxisome proliferator-activated receptor $\gamma$, TZDs such as pioglitazone improve insulin sensitivity at the level of adipose tissue, liver and muscle by protecting non-adipose tissues against lipid overload, balancing the secretion of adipocytokines and inhibition of lipolysis [104, 105]. By improving insulin sensitivity, TZDS may even delay the onset of diabetes mellitus in patients with impaired glucose tolerance [106]. Several clinical trials investigated the effects of TZDs in patients with NAFLD [107]. The largest one using pioglitazone enrolled non-diabetic patients with biopsy-proven NASH [108] and demonstrated improvements in steatosis, liver enzymes and inflammation. Interestingly a greater proportion of patients on pioglitazone had an entirely resolution of steatohepatitis on liver biopsy at the end of treatment. Identification of predictors of response will be crucial along with studies to assess long-term benefits, particularly since the beneficial effects appear to be short-lived after halting treatment [109]. Weight gain of up to $6 \mathrm{~kg}$ within the first 12 months of treatment is almost universal [110] and may represent either adipose tissue expansion or water retention. Since long-term use of TZDs is possibly linked to congestive heart failure, reduced bone mineral density with fractures and increased incidence of bladder cancer [111], risks and benefits must be carefully weighted and patients monitored once treatment has been initiated. At least the increased risk for bladder cancer was not confirmed in a recent global study involving six cohorts of diabetic patients [112].

By targeting the nuclear farnesoid $X$ receptor (FXR), bile acids have been shown to not only be detergent-like molecules but also key signaling molecules involved in pathways that regulate bile acid, lipid and glucose metabolism [113]. Activation of FXR has also anti-inflammatory and anti-fibrotic effects, respectively [114]. By improving insulin sensitivity, FXR agonists such as obeticholic acid (OCA), a 6 $\alpha$-ethyl derivative of chenodeocxcholic acid, may represent promising drugs particularly for the treatment of diabetic patients with NAFLD $[115,116]$. When given to patients with diabetes mellitus and NAFLD in a placebo-controlled trial [117], OCA indeed increased insulin sensitivity and also resulted in a decrease in body weight. The effect of OCA has been further explored in a large number of non-cirrhotic patients with biopsy-proven NASH [118]. This placebo-controlled FLINT trial was stopped early due to OCA mediated improvement in liver histology. Studies are ongoing to explore the anti-inflammatory and anti-fibrotic effects of OCA as well as potential cardiovascular consequences of an increase in low density lipoprotein cholesterol observed in the FLINT trial.

Peroxisome proliferator-activated receptors (PPARs) are fatty 
acid-activated receptors [119]. While single PPAR $\alpha$ agonists like fibrates do not appear to be beneficial in patients with NAFLD [120], the dual PPAR $\alpha / \delta$ agonist GFT505 has recently been shown to be liver protective with regard to steatosis, inflammation and fibrosis in a PPAR-dependent and -independent fashion [121]. GFT505 has also been shown to improve insulin sensitivity, dyslipidemia and elevated liver enzymes in obese patients with dyslipidemia or impaired glucose metabolism [122]. Of note, GFT505 exhibited antifibrotic effects independent of insulin resistance and metabolic abnormalities [121]. These findings prompted a placebo controlled study in patients with biopsyproven NASH that aims at demonstrating reversal of NASH without worsening of fibrosis.

\section{Lipid-lowering agents}

Cardiovascular disease resulting from dyslipidemia is the major cause of morbidity and mortality for individuals with diabetes mellitus. Therefore it is not surprising that patients are often treated with statins to minimize cardiovascular mortality. A substantial number of patients receiving statin treatment for cardiovascular protection have coexisting NAFLD and that on its own is known for fluctuating liver enzymes [17]. Therefore liver enzyme elevations during statin therapy do not necessarily reflect drug-induced liver injury. Statin toxicity is very low and the US Food and Drug Administration followed recommendations of a liver expert panel [123] and dropped the requirement of liver enzyme monitoring during statin therapy. More recently clinical trials and meta-analyses have shown that statin therapy appears to be associated with new-onset diabetes mellitus. As cardiovascular benefits of statins outweigh this risk, no change in clinical practice is currently recommended [124]. The effects of statins on liver histology are limited and thus statins do not have a role in reversing NASH or preventing progression of NAFLD. Unless proven otherwise, the sole indication for statins in NAFLD is treatment of dyslipidemia [59]. Considering NAFLD being independently associated with an increased cardiovascular risk, statin efficacy in patients with NAFLD may need to be measured as reduction in cardiovascular events, rather than improvement in liver histology [125] and likely outweigh the current lack of specific histologic improvement.

\section{Outlook}

Over the last twenty-five years since its initial description, tremendous progress has been made in our understanding of nonalcoholic fatty liver disease. Several challenges however remain and include the need to develop more precise tools that allow us to identify patients with and without diabetes mellitus that are at particular risk to develop steatohepatitis and potentially progress to liver cirrhosis. Hepatocellular carcinoma does occur in non-cirrhotic patients and therefore it will be of clinical importance to identify those individuals at minimal risk to allow for cost-effective screening efforts. Albeit liver histology likely will remain part of the work-up for another couple of years and be an important component to assess efficacy of new drugs under development, future research needs to explore improved methods of noninvasive monitoring of disease activity. New pharmacological agents currently under development for diabetes mellitus may also be efficacious for the treatment of NAFLD, but drug development targeting different pathways in the disease pathogenesis also represents an unmet need. Expectations from patients for prescription NAFLD drugs are high and have overcome the current need for a liver biopsy needed for recruitment into large placebo-controlled trials. The future looks bright. 


\section{Reference}

1 Mokdad AH, Bowman BA, Ford ES, Vinicor F, Marks JS, et al. (2001) The continuing epidemics of obesity and diabetes in the United States. JAMA 286: 1195-1200.

2 Guariguata L, Whiting DR, Hambleton I, Beagley J, Linnenkamp U, et al. (2014) Global estimates of diabetes prevalence for 2013 and projections for 2035. Diabetes Res Clin Pract 103: 137-149.

3 Whiting DR, Guariguata L, Weil C, Shaw J (2011) IDF diabetes atlas: global estimates of the prevalence of diabetes for 2011 and 2030. Diabetes Res Clin Pract 94: 311-321.

4 Muggeo M, Verlato G, Bonora E, Bressan F, Girotto S, et al. (1995) The Verona diabetes study: a population-based survey on known diabetes mellitus prevalence and 5-year all-cause mortality. Diabetologia 38: 318-325.

5 de Marco R, Locatelli F, Zoppini G, Verlato G, Bonora E, et al. (1999) Cause-specific mortality in type 2 diabetes. The Verona Diabetes Study. Diabetes Care 22: 756-761.

6 Saponaro C, Gaggini M, Gastaldelli A (2015) Nonalcoholic fatty liver disease and type 2 diabetes: common pathophysiologic mechanisms. Curr Diab Rep 15: 607.

7 Ekstedt M, Franzacn LE, Mathiesen UL, Thorelius L, Holmqvist M, et al. (2006) Long-term follow-up of patients with NAFLD and elevated liver enzymes. Hepatology 44: 865-873.

8 Sanderberg C, Stayl P, Askling J, Glaumann H, Lindberg G, et al. (2010) Decreased survival of subjects with elevated liver function tests during a 28-year follow-up. Hepatology 51: 595-602.

9 Angulo P, Kleiner DE, Dam-Larsen S, Adams LA, Bjornsson ES, et al. (2015) Liver Fibrosis, but No Other Histologic Features, Is Associated With Long-term Outcomes of Patients with Nonalcoholic Fatty Liver Disease. Gastroenterology 149: 389-397.

10 Wieland AC, Quallick M, Truesdale A, Mettler P, Bambha KM (2013) Identifying practice gaps to optimize medical care for patients with nonalcoholic fatty liver disease. Dig Dis Sci 58: 2809-2816.

11 Kallman JB, Arsalla A, Park V, Dhungel S, Bhatia P, et al. (2009) Screening for hepatitis $B, C$ and non-alcoholic fatty liver disease: a survey of community-based physicians. Aliment Pharmacol Ther 29: 1019-1024.

12 Bergqvist CJ, Skoien R, Horsfall L, Clouston AD, Jonsson JR, et al. (2013) Awareness and opinions of non-alcoholic fatty liver disease by hospital specialists. Intern Med J 43: 247-253.

13 Armstrong MJ, Hazlehurst JM, Parker R, Koushiappi E, Mann J, et al. (2014) Severe asymptomatic non-alcoholic fatty liver disease in routine diabetes care; a multi-disciplinary team approach to diagnosis and management QJM 107: 33-41.

14 Wong VW, Wong GL, Yip GW, Lo AO, Limquiaco J, et al. (2011) Coronary artery disease and cardiovascular outcomes in patients with non-alcoholic fatty liver disease. Gut 60: 1721-1727.

15 Targher G, Bertolini L, Padovani R, Rodella S, Tessari R, et al. (2007) Prevalence of nonalcoholic fatty liver disease and its association with cardiovascular disease among type 2 diabetic patients. Diabetes Care 30: 1212-1218.

16 Fracanzani AL, Valenti L, Bugianesi E, Andreoletti M, Colli A, et al. (2008) Risk of severe liver disease in nonalcoholic fatty liver disease with normal aminotransferase levels: a role for insulin resistance and diabetes. Hepatology 48: 792-798.
17 Mofrad P, Contos MJ, Haque M, Sargeant C, Fisher RA, et al. (2003) Clinical and histologic spectrum of nonalcoholic fatty liver disease associated with normal ALT values. Hepatology 37: 1286-1292.

18 Portillo S P, Bril F, Maximos M, Lomonaco R, Biernacki D, et al. (2015) High prevalence of nonalcoholic fatty liver disease in patients with type 2 diabetes mellitus and normal plasma aminotransferase levels. J Clin Endocrinol Metab 100: 2231-2238.

19 Leung CM, Lai LS, Wong WH, Chan KH, Luk YW, et al. (2009) Nonalcoholic fatty liver disease: an expanding problem with low levels of awareness in Hong Kong. J Gastroenterol Hepatol 24: 1786-1790.

20 Wieland AC, Mettler P, McDermott MT, Crane LA, Cicutto LC, et al. (2015) Low awareness of nonalcoholic fatty liver disease among patients at high metabolic risk. J Clin Gastroenterol 49: e6-6e10.

21 Browning JD, Szczepaniak LS, Dobbins R, Nuremberg P, Horton JD, et al. (2004) Prevalence of hepatic steatosis in an urban population in the United States: impact of ethnicity. Hepatology 40: 1387-1395.

22 Tolman KG, Fonseca V, Dalpiaz A, Tan MH (2007) Spectrum of liver disease in type 2 diabetes and management of patients with diabetes and liver disease. Diabetes Care 30: 734-743.

23 Silverman JF, O'Brien KF, Long S, Leggett N, Khazanie PG, et al. (1990) Liver pathology in morbidly obese patients with and without diabetes. Am J Gastroenterol 85: 1349-1355.

24 Jimba S, Nakagami T, Takahashi M, Wakamatsu T, Hirota Y, et al. (2005) Prevalence of non-alcoholic fatty liver disease and its association with impaired glucose metabolism in Japanese adults. Diabet Med 22: 1141-1145.

25 Sung KC, Kim BS, Cho YK, Park DI, Woo S, et al. (2012) Predicting incident fatty liver using simple cardio-metabolic risk factors at baseline. BMC Gastroenterol 12: 84.

26 Adams LA, Harmsen S, St Sauver JL, Charatcharoenwitthaya P, Enders FB, et al. (2010) Nonalcoholic fatty liver disease increases risk of death among patients with diabetes: a community-based cohort study. Am J Gastroenterol 105: 1567-1573.

27 Williams CD, Stengel J, Asike MI, Torres DM, Shaw J, et al. (2011) Prevalence of nonalcoholic fatty liver disease and nonalcoholic steatohepatitis among a large middle-aged population utilizing ultrasound and liver biopsy: a prospective study. Gastroenterology 140: $124-131$

28 Park SK, Seo MH, Shin HC, Ryoo JH (2013) Clinical availability of nonalcoholic fatty liver disease as an early predictor of type 2 diabees mellitus in Korean men: 5-year prospective cohort study. Hepatology 57: 1378-1383.

29 Bae JC, Rhee EJ, Lee WY, Park SE, Park CY, et al. (2011) Combined effect of nonalcoholic fatty liver disease and impaired fasting glucose on the development of type 2 diabetes: a 4-year retrospective longitudinal study. Diabetes Care 34: 727-729.

30 Yamazaki H, Tsuboya T, Tsuji K, Dohke M, Maguchi H (2015) Independent association between improvement of nonalcoholic fatty liver disease and reduced incidence of type 2 diabetes. Diabetes Care 38: 1673-1679.

31 Scaglioni F, Ciccia S, Marino M, Bedogni G, Bellentani S (2011) ASH and NASH. Dig Dis 29: 202-210.

32 Maheshwari A, Thuluvath PJ (2006) Cryptogenic cirrhosis and NAFLD: are they related? Am J Gastroenterol 101: 664-668.

33 Shetty A, Wilson S, Kuo P, Laurin JL, Howell CD, et al. (2000) Liver 
transplantation improves cirrhosis-associated impaired oral glucose tolerance. Transplantation 69: 2451-2454.

34 Marchesini G, Bianchi GP, Forlani G, Rusticali AG, Patrono D, et al. (1987) Insulin resistance is the main determinant of impaired glucose tolerance in patients with liver cirrhosis. Dig Dis Sci 32: 1118-1124.

35 Del Vecchio Blanco C, Gentile S, Marmo R, Carbone L, Coltorti M (1990) Alterations of glucose metabolism in chronic liver disease. Diabetes Res Clin Pract 8: 29-36.

36 Adami HO, Chow WH, Nyracn O, Berne C, Linet MS, et al. (1996) Excess risk of primary liver cancer in patients with diabetes mellitus. J Natl Cancer Inst 88: 1472-1477.

37 El-Serag HB, Tran T, Everhart JE (2004) Diabetes increases the risk of chronic liver disease and hepatocellular carcinoma. Gastroenterology 126: 460-468.

38 Kawamura Y, Arase Y, Ikeda K, Seko Y, Imai N, et al. (2012) Large-scale long-term follow-up study of Japanese patients with non-alcoholic Fatty liver disease for the onset of hepatocellular carcinoma. Am J Gastroenterol 107: 253-261.

39 Sanyal A, Poklepovic A, Moyneur E, Barghout V (2010) Populationbased risk factors and resource utilization for HCC: US perspective. Curr Med Res Opin 26: 2183-2191.

40 Ascha MS, Hanouneh IA, Lopez R, Tamimi TA, Feldstein AF, et al. (2010) The incidence and risk factors of hepatocellular carcinoma in patients with nonalcoholic steatohepatitis. Hepatology 51: 19721978.

41 Balkau B, Eschwege E, Ducimetiere P, Richard JL, Warnet JM (1991) The high risk of death by alcohol related diseases in subjects diagnosed as diabetic and impaired glucose tolerant: the Paris Prospective Study after 15 years of follow-up. J Clin Epidemiol 44: 465-474.

42 Creutzfeldt W, Frerichs H, Sickinger K (1970) Liver diseases and diabetes mellitus. Prog Liver Dis 3: 371-407.

43 Harman DJ, Kaye PV, Harris R, Suzuki A, Gazis A, et al. (2014) Prevalence and natural history of histologically proven chronic liver disease in a longitudinal cohort of patients with type 1 diabetes. Hepatology 60: 158-168.

44 Yusuf S, Hawken S, Ounpuu S, Dans T, Avezum A, et al. (2004) Effect of potentially modifiable risk factors associated with myocardial infarction in 52 countries (the INTERHEART study): case-control study. Lancet 364: 937-952.

45 Pacana T, Fuchs M (2012) The cardiovascular link to nonalcoholic fatty liver disease: a critical analysis. Clin Liver Dis 16: 599-613.

46 Bhatia LS, Curzen NP, Calder PC, Byrne CD (2012) Non-alcoholic fatty liver disease: a new and important cardiovascular risk factor? Eur Heart J 33: 1190-1200.

47 Targher G, Day CP, Bonora E (2010) Risk of cardiovascular disease in patients with nonalcoholic fatty liver disease. N Engl J Med 363 : 1341-1350.

48 Guleria A, Duseja A, Kalra N, Das A, Dhiman R, et al. (2013) Patients with non-alcoholic fatty liver disease (NAFLD) have an increased risk of atherosclerosis and cardiovascular disease. Trop Gastroenterol 34: 74-82.

49 Rafiq N, Bai C, Fang Y, Srishord M, McCullough A, et al. (2009) Long-term follow-up of patients with nonalcoholic fatty liver. Clin Gastroenterol Hepatol 7: 234-238.
50 Sanyal AJ, Banas C, Sargeant C, Luketic VA, Sterling RK, et al. (2006) Similarities and differences in outcomes of cirrhosis due to nonalcoholic steatohepatitis and hepatitis C. Hepatology 43: 682-689.

51 Anstee QM, Day CP (2013) The genetics of NAFLD. Nat Rev Gastroenterol Hepatol 10: 645-655.

52 Naik A, Koajir R, Rozman D (2013) Genomic aspects of NAFLD pathogenesis. Genomics 102: 84-95.

53 Lyssenko V, Lupi R, Marchetti P, Del Guerra S, Orho-Melander M, et al. (2007) Mechanisms by which common variants in the TCF7L2 gene increase risk of type 2 diabetes. J Clin Invest 117: 2155-2163.

54 Musso G, Gambino R, Pacini G, Pagano G, Durazzo M, et al. (2009) Transcription factor 7-like 2 polymorphism modulates glucose and lipid homeostasis, adipokine profile, and hepatocyte apoptosis in NASH. Hepatology 49: 426-435.

55 Li H, Xu R, Peng X, Wang Y, Wang T (2013) Association of glucokinase regulatory protein polymorphism with type 2 diabetes and fasting plasma glucose: a meta-analysis. Mol Biol Rep 40: 3935-3942.

56 Musso G, Cassader M, Bo S, De Michieli F, Gambino R (2013) Sterol regulatory element-binding factor 2 (SREBF-2) predicts 7-year NAFLD incidence and severity of liver disease and lipoprotein and glucose dysmetabolism. Diabetes 62: 1109-1120.

57 Feinberg AP (2007) Phenotypic plasticity and the epigenetics of human disease. Nature 447: 433-440.

58 Braun R, Buetow K (2011) Pathways of distinction analysis: a new technique for multi-SNP analysis of GWAS data. PLoS Genet 7: e1002101.

59 Chalasani N, Younossi Z, Lavine JE, Diehl AM, Brunt EM, et al. (2012) The diagnosis and management of non-alcoholic fatty liver disease: practice guideline by the American Association for the Study of Liver Diseases, American College of Gastroenterology, and the American Gastroenterological Association. Hepatology 55: 2005-2023.

60 Hernaez R, Lazo M, Bonekamp S, Kamel I, Brancati FL, et al. (2011) Diagnostic accuracy and reliability of ultrasonography for the detection of fatty liver: a meta-analysis. Hepatology 54: 1082-1090.

61 Razavizade M, Jamali R, Arj A, Talari H (2012) Serum parameters predict the severity of ultrasonographic findings in non-alcoholic fatty liver disease. Hepatobiliary Pancreat Dis Int 11: 513-520.

62 Schwenzer NF, Springer F, Schraml C, Stefan N, Machann J, et al. (2009) Non-invasive assessment and quantification of liver steatosis by ultrasound, computed tomography and magnetic resonance. $J$ Hepatol 51: 433-445.

63 Piccinino F, Sagnelli E, Pasquale G, Giusti G (1986) Complications following percutaneous liver biopsy. A multicentre retrospective study on 68,276 biopsies. J Hepatol 2: 165-173.

64 Ratziu V, Charlotte F, Heurtier A, Gombert S, Giral P, et al. (2005) Sampling variability of liver biopsy in nonalcoholic fatty liver disease. Gastroenterology 128: 1898-1906.

65 Harrison SA, Oliver D, Arnold HL, Gogia S, Neuschwander-Tetri BA (2008) Development and validation of a simple NAFLD clinical scoring system for identifying patients without advanced disease. Gut 57: 1441-1447.

66 McPherson S, Stewart SF, Henderson E, Burt AD, Day CP (2010) Simple non-invasive fibrosis scoring systems can reliably exclude advanced fibrosis in patients with non-alcoholic fatty liver disease. Gut 59: 1265-1269. 
67 McPherson S, Henderson E, Burt AD, Day CP, Anstee QM (2014) Serum immunoglobulin levels predict fibrosis in patients with nonalcoholic fatty liver disease. J Hepatol 60: 1055-1062.

68 Shah AG, Lydecker A, Murray K, Tetri BN, Contos MJ, et al. (2009) Comparison of noninvasive markers of fibrosis in patients with nonalcoholic fatty liver disease. Clin Gastroenterol Hepatol 7: 11041112.

69 Morling JR, Fallowfield JA, Guha IN, Nee LD, Glancy S, et al. (2014) Using non-invasive biomarkers to identify hepatic fibrosis in people with type 2 diabetes mellitus: the Edinburgh type 2 diabetes study. J Hepatol 60: 384-391.

70 Marchesini G, Brizi M, Morselli-Labate AM, Bianchi G, Bugianesi E, et al. (1999) Association of nonalcoholic fatty liver disease with insulin resistance. Am J Med 107: 450-455.

71 Bazick J, Donithan M, Neuschwander-Tetri BA, Kleiner D, Brunt EM, et al. (2015) Clinical Model for NASH and Advanced Fibrosis in Adult Patients With Diabetes and NAFLD: Guidelines for Referral in NAFLD. Diabetes Care 38: 1347-1355.

72 Cobbold JF, Patel D, Taylor-Robinson SD (2012) Assessment of inflammation and fibrosis in non-alcoholic fatty liver disease by imaging-based techniques. J Gastroenterol Hepatol 27: 1281-1292.

73 Kwok R, Choi KC, Wong GL, Zhang Y, Chan HL, et al. (2015) Screening diabetic patients for non-alcoholic fatty liver disease with controlled attenuation parameter and liver stiffness: a prospective cohort study. Gut

74 Dumas ME, Kinross J, Nicholson JK (2014) Metabolic phenotyping and systems biology approaches to understanding metabolic syndrome and fatty liver disease. Gastroenterology 146: 46-62.

75 Fuchs M (2015) New medical treatment strategies for nonalcoholic steatohepatitis. Curr Treat Options Gastroenterol 13: 259-273.

76 Clark JM (2006) Weight loss as a treatment for nonalcoholic fatty liver disease. J Clin Gastroenterol 40 Suppl 1: S39-43.

77 Evert AB, Boucher JL, Cypress M, Dunbar SA, Franz MJ, et al. (2013) Nutrition therapy recommendations for the management of adults with diabetes. Diabetes Care 36: 3821-3842.

78 Zelber-Sagi S, Nitzan-Kaluski D, Goldsmith R, Webb M, Zvibel I, et al. (2008) Role of leisure-time physical activity in nonalcoholic fatty liver disease: a population-based study. Hepatology 48: 1791-1798.

79 Boulac NG, Haddad E, Kenny GP, Wells GA, Sigal RJ (2001) Effects of exercise on glycemic control and body mass in type 2 diabetes mellitus: a meta-analysis of controlled clinical trials. JAMA 286 1218-1227.

80 Oza N, Eguchi Y, Mizuta T, Ishibashi E, Kitajima Y, et al. (2009) A pilot trial of body weight reduction for nonalcoholic fatty liver disease with a home-based lifestyle modification intervention delivered in collaboration with interdisciplinary medical staff. J Gastroenterol 44: 1203-1208.

81 Johnson NA, Sachinwalla T, Walton DW, Smith K, Armstrong A, et al. (2009) Aerobic exercise training reduces hepatic and visceral lipids in obese individuals without weight loss. Hepatology 50: 1105-1112.

82 Kistler KD, Brunt EM, Clark JM, Diehl AM, Sallis JF, et al. (2011) Physical activity recommendations, exercise intensity, and histological severity of nonalcoholic fatty liver disease. Am J Gastroenterol 106 460-468.

83 St George A, Bauman A, Johnston A, Farrell G, Chey T, et al. (2009)
Independent effects of physical activity in patients with nonalcoholic fatty liver disease. Hepatology 50: 68-76.

84. Thoma C, Day CP, Trenell MI (2012) Lifestyle interventions for the treatment of non-alcoholic fatty liver disease in adults: a systematic review. J Hepatol 56: 255-266.

85 Newton JL, Jones DE, Henderson E, Kane L, Wilton K, et al. (2008) Fatigue in non-alcoholic fatty liver disease (NAFLD) is significant and associates with inactivity and excessive daytime sleepiness but not with liver disease severity or insulin resistance. Gut 57: 807-813.

86 Ouyang X, Cirillo P, Sautin Y, McCall S, Bruchette JL, et al. (2008) Fructose consumption as a risk factor for non-alcoholic fatty liver disease. J Hepatol 48: 993-999.

87 Zelber-Sagi S, Nitzan-Kaluski D, Goldsmith R, Webb M, Blendis L, et al. (2007) Long term nutritional intake and the risk for non-alcoholic fatty liver disease (NAFLD): a population based study. J Hepatol 47: 711-717.

88 Musso G, Gambino R, De Michieli F, Cassader M, Rizzetto M, et al. (2003) Dietary habits and their relations to insulin resistance and postprandial lipemia in nonalcoholic steatohepatitis. Hepatology 37 909-916.

89 Lindqvist A, Baelemans A, Erlanson-Albertsson C (2008) Effects of sucrose, glucose and fructose on peripheral and central appetite signals. Regul Pept 150: 26-32.

90 Ryan MC, Itsiopoulos C, Thodis T, Ward G, Trost N, et al. (2013) The Mediterranean diet improves hepatic steatosis and insulin sensitivity in individuals with non-alcoholic fatty liver disease. J Hepatol 59: 138-143.

91 Conlon BA, Beasley JM, Aebersold K, Jhangiani SS, Wylie-Rosett J (2013) Nutritional management of insulin resistance in nonalcoholic fatty liver disease (NAFLD). Nutrients 5: 4093-4114.

92 Julius U (2003) Fat modification in the diabetes diet. Exp Clin Endocrinol Diabetes 111: 60-65.

93 Rodraguez-Villar C, Pacrez-Heras A, Mercadac I, Casals E, Ros E (2004) Comparison of a high-carbohydrate and a high-monounsaturated fat, olive oil-rich diet on the susceptibility of LDL to oxidative modification in subjects with Type 2 diabetes mellitus. Diabet Med 21: 142-149.

94 Lombardo YB, Chicco AG (2006) Effects of dietary polyunsaturated n-3 fatty acids on dyslipidemia and insulin resistance in rodents and humans. A review. J Nutr Biochem 17: 1-13.

95 McCarthy EM, Rinella ME (2012) The role of diet and nutrient composition in nonalcoholic Fatty liver disease. J Acad Nutr Diet 112: 401-409.

96 Centis E, Marzocchi R, Di Domizio S, Ciaravella MF, Marchesini G (2010) The effect of lifestyle changes in non-alcoholic fatty liver disease. Dig Dis 28: 267-273.

97 Stewart KE, Haller DL, Sargeant C, Levenson JL, Puri P, et al. (2015) Readiness for behaviour change in non-alcoholic fatty liver disease: implications for multidisciplinary care models. Liver Int 35: 936-943.

98 Stumvoll M, Nurjhan N, Perriello G, Dailey G, Gerich JE (1995) Metabolic effects of metformin in non-insulin-dependent diabetes mellitus. N Engl J Med 333: 550-554.

99 Doycheva I, Loomba R (2014) Effect of metformin on ballooning degeneration in nonalcoholic steatohepatitis (NASH): when to use metformin in nonalcoholic fatty liver disease (NAFLD). Adv Ther 31: 30-43. 
100 Donadon V, Balbi M, Mas MD, Casarin P, Zanette G (2010) Metformin and reduced risk of hepatocellular carcinoma in diabetic patients with chronic liver disease. Liver Int 30: 750-758.

101 Zamek-Gliszczynski MJ, Bao JQ, Day JS, Higgins JW (2013) Metformin sinusoidal efflux from the liver is consistent with negligible biliary excretion and absence of enterohepatic cycling. Drug Metab Dispos 41: 1967-1971.

102 Graham GG, Punt J, Arora M, Day RO, Doogue MP, et al. (2011) Clinical pharmacokinetics of metformin. Clin Pharmacokinet 50: 81-98.

103 Lalau JD (2010) Lactic acidosis induced by metformin: incidence, management and prevention. Drug Saf 33: 727-740.

104 Bourron O, Daval M, Hajduch E, Servant JM, Gautier JF, et al. (2010) Biguanides and thiazolidinediones inhibit stimulated lipolysis in human adipocytes through activation of AMP-activated protein kinase. Diabetologia 53: 768-778.

105 Charbonnel B, DeFronzo R, Davidson J, Schmitz O, Birkeland K, et al. (2010) Pioglitazone use in combination with insulin in the prospective pioglitazone clinical trial in macrovascular events study (PROactive19). J Clin Endocrinol Metab 95: 2163-2171.

106 DeFronzo RA, Tripathy D, Schwenke DC, Banerji M, Bray GA, et al. (2011) Pioglitazone for diabetes prevention in impaired glucose tolerance. N Engl J Med 364: 1104-1115.

107 Van Wagner LB, Rinella ME (2011) The role of insulin-sensitizing agents in the treatment of nonalcoholic steatohepatitis. Therap Adv Gastroenterol 4: 249-263.

108 Sanyal AJ, Chalasani N, Kowdley KV, McCullough A, Diehl AM, et al. (2010) Pioglitazone, vitamin E, or placebo for nonalcoholic steatohepatitis. N Engl J Med 362: 1675-1685.

109 Lutchman G, Modi A, Kleiner DE, Promrat K, Heller T, et al. (2007) The effects of discontinuing pioglitazone in patients with nonalcoholic steatohepatitis. Hepatology 46: 424-429.

110 Musso G, Gambino R, Cassader M, Pagano G (2010) A meta-analysis of randomized trials for the treatment of nonalcoholic fatty liver disease. Hepatology 52: 79-104.

111 Yau H, Rivera K, Lomonaco R, Cusi K (2013) The future of thiazolidinedione therapy in the management of type 2 diabetes mellitus. Curr Diab Rep 13: 329-341.

112 Levin D, Bell S, Sund R, Hartikainen SA, Tuomilehto J, et al. (2015) Pioglitazone and bladder cancer risk: a multipopulation pooled, cumulative exposure analysis. Diabetologia 58: 493-504.

113 Lefebvre P, Cariou B, Lien F, Kuipers F, Staels B (2009) Role of bile acids and bile acid receptors in metabolic regulation. Physiol Rev 89: 147-191.
114 Zhang S, Wang J, Liu Q, Harnish DC (2009) Farnesoid X receptor agonist WAY-362450 attenuates liver inflammation and fibrosis in murine model of non-alcoholic steatohepatitis. J Hepatol 51: 380-388.

115 Adorini L, Pruzanski M, Shapiro D (2012) Farnesoid X receptor targeting to treat nonalcoholic steatohepatitis. Drug Discov Today 17: 988-997.

116 Fuchs M (2012) Non-alcoholic Fatty liver disease: the bile Acidactivated farnesoid $\mathrm{x}$ receptor as an emerging treatment target. J Lipids 2012: 934396.

117 Mudaliar S, Henry RR, Sanyal AJ, Morrow L, Marschall HU, et al. (2013) Efficacy and safety of the farnesoid $X$ receptor agonist obeticholic acid in patients with type 2 diabetes and nonalcoholic fatty liver disease. Gastroenterology 145: 574-582.

118 Neuschwander-Tetri BA, Loomba R, Sanyal AJ, Lavine JE, Van Natta ML. et al. (2015) Farnesoid X nuclear receptor ligand obeticholic acid for non-alcoholic steatohepatitis (FLINT): a multicentre, randomized, placebo-controlled trial. Lancet 385: 956-965.

119 Staels B, Fruchart JC (2005) Therapeutic roles of peroxisome proliferator-activated receptor agonists. Diabetes 54: 2460-2470.

120 Laurin J, Lindor KD, Crippin JS, Gossard A, Gores GJ, et al. (1996) Ursodeoxycholic acid or clofibrate in the treatment of non-alcoholinduced steatohepatitis: a pilot study. Hepatology 23: 1464-1467.

121 Staels B, Rubenstrunk A, Noel B, Rigou G, Delataille P, et al. (2013) Hepatoprotective effects of the dual peroxisome proliferatoractivated receptor alpha/delta agonist, GFT505, in rodents of nonalcoholic fatty liver disease/nonalcoholic steatohepatitis. Hepatology 58: 1941-1952.

122 Cariou B, Zaar Y, Staels B, Bruckert E (2011) Effects of the new dual PPAR $-\hat{l} \pm$ agonist GFT505 on lipid and glucose homeostasis in abdominally obese patients with combined dyslipidemia or impaired glucose metabolism. Diabetes Care 34: 2008-2014.

123 Cohen DE, Anania FA, Chalasani N; National Lipid Association Statin Safety Task Force Liver Expert Panel (2006) An assessment of statin safety by hepatologists. Am J Cardiol 97: 77C-81C.

124 Sattar N, Taskinen MR (2012) Statins are diabetogenic--myth or reality? Atheroscler Suppl 13: 1-10.

125 Athyros VG, Tziomalos K, Gossios TD, Griva T, Anagnostis P, et al. (2010) Safety and efficacy of long-term statin treatment for cardiovascular events in patients with coronary heart disease and abnormal liver tests in the Greek Atorvastatin and Coronary Heart Disease Evaluation (GREACE) Study: a post-hoc analysis. Lancet 376: 1916-1922. 